Acta Technologica Agriculturae 3

Nitra, Slovaca Universitas Agriculturae Nitriae, 2020, pp. 118-125

\title{
PREDICTIONS OF THE APPLE BRUISE VOLUME ON THE BASIS OF IMPACT ENERGY OR MAXIMUM CONTACT FORCE USING ADAPTIVE NEURO-FUZZY INFERENCE SYSTEM (ANFIS)
}

\author{
Farhad FAZEL ${ }^{1}$, Abdollah GOLMOHAMMADI ${ }^{1 *}$, Gholamhossein SHAHGHOLI ${ }^{1}$, Ebrahim AHMADI ${ }^{2}$ \\ ${ }^{1}$ University of Mohaghegh Ardabili, Ardabil, Iran \\ ${ }^{2}$ Bu-Ali Sina University, Hamedan, Iran
}

\begin{abstract}
Fruit quality drops significantly due to physical impacts and contact forces. Stress on the fruit surface during harvesting, transportation and storage operations causes bruising in its tissue and eventually result in fruit failure. Therefore, prediction of the bruise volume caused by impacts can be very important. In this research, adaptive neuro fuzzy inference system (ANFIS) was used to predict the bruise volume caused by the impacts on apples. The input parameters were the maximum contact force or impact energy; curvature radius at the contact point; temperature; and fruit mass. Its response was the bruise volume. The results show that the ANFIS models operated better in the bruise volume prediction than regression models. Between different available ANFIS models, the model based on the grid partitioning showed the best results with a mean squared error of MSE $=0.00015941$, which was less than value showed by the sub-clustering mode. However, its implementation time to reach a fixed error was longer. Eventually, impact energy-based models, in contrast to maximum contact force-based models, were more capable in terms of the apple bruising prediction.
\end{abstract}

Keywords: stress; transport; contact point; curvature radius

Annually, large quantities of agricultural products are degraded due to bruise and other mechanical damage during harvesting, transportation, storage and packaging. One of the most important reasons for deterioration of the quality of fresh fruit market is bruising (Ahmadi et al., 2016). Common mechanical damage during harvesting and transportation of fruits is defined as plastic deformation, surface rupture and tissue destruction due to external forces (Lewis et al., 2008). The factors affecting damage severity are fruit falling height, contact energy, number of contact points, type of contact surface and size and ripeness of the fruit (Roth et al., 2005). Identifying the impact situation, which can cause bruises, is essential to improve methods and equipment for harvesting, transportation and grading process (Van Linden et al., 2006). Three important factors cause fruit damage: impact, vibration and compressive force (Diezma et al., 2006).

In order to provide models for fruit bruise prediction, it is important to determine the fruit physical properties. In recent years, certain types of equipment have been developed to simulate the dynamic impact, from among which the impact table and the pendulum device are the most applicable for impact testing of agricultural products. Since the impact location on the fruit is not controlled in the table, using pendulum to make impact and fruit bruises appears to be more reasonable (Abedi and Ahmadi, 2013). The bruise volume prediction models include main and minor variables, which are considered independent variables. The main variables depend on the impact characteristics, and include factors such as the maximum contact force, impact energy, impact time, and falling height. The sub-variables are related to the fruit characteristics, such as temperature, stiffness, storage time, harvesting history and curvature radius (Diezma et al., 2006). Among main variables, two variables - impact energy and the maximum contact force - are mostly used for determining the bruise volume (Van Zeebroeck et al., 2007). They have both advantages and disadvantages. A model, in which the maximum contact force is an independent variable, can be generalized to materials with different curvature radius and properties. For example, bruise damage will be greater when an apple falls on a hard plate than on a second apple. But in a case of impact energy as an independent variable, the estimated bruise is the same for both. Disadvantage of the model, in which the maximum contact force is used as an independent variable, lies in the fact that contact force is a function of sub-variables, such as temperature, stiffness, curvature radius, etc. Therefore, without taking these variables into account, the estimated bruise will be inaccurate. However, model based on impact energy criterion does not have these defects (Van Zeebroeck et al., 2007). The bruise volume and dynamic yield pressure are calculated as dependent variables in the bruise prediction models (Menesatti and Paglia, 2001).

In the past, mathematical models were used to find the relationship between inputs and outputs in a process.

Contact address: Abdollah Golmohammadi, University of Mohaghegh Ardabili, Ardabil, Iran e-mail:agolmohammadi42@yahoo.com 
However, this classical logic approach requires a precise definition of the mathematical model equations described for that phenomenon. Today, it has been proven that in many applications that fuzzy logic (FL) is superior to the classical mathematical procedures for achieving artificial intelligence (Al) solutions goals, since FL is conceptually very simple and flexible. In fact, it is easy to set up a fuzzy system to solve a complex problem using organized if-then rules (Moinfar and Shahgholi, 2019). In recent years, learning techniques have been widely used to develop uncontrolled systems for assessing the food quality (Du and Sun, 2006). In contrast to other learning techniques, ANFIS has higher training speed, effective learning algorithms and software simplicity (Jang and Sun, 1997), as well as faster convergence and better results when used without any prior knowledge (Altug et al., 1999). Hence, ANFIS as a modelling tool has been used in agricultural technology (Zheng et al., 2011); food rheology (Karaman and Kayacier, 2011); food processing (Amiryousefi et al., 2011); performance prediction (Khoshnevisan et al., 2014); and various extractions of plants and vegetables (Jhin and Hwang, 2014). Models of artificial intelligence have various applications, including in apple bruising prediction (Barreiro et al., 1997), fruit grading (Effendi et al., 2010), and apple drying process modelling (Khoshhal et al., 2010). The purpose of this study was to develop the artificial intelligence models for predicting the apple bruising using the impact energy or maximum contact force with fruit properties, such as temperature, density, and curvature radius as independent variables.

\section{Material and methods}

For the purposes of experiment, certain numbers of apples were taken several times in 2014 from the Shend Abad Shabestar gardens. Apple samples were of Golden Delicious variety. To prevent any damage to the fruit, the harvesting was carried out manually and apples were carefully placed in plastic boxes for transportation. The fruits were stored in a refrigerator at a temperature of $3{ }^{\circ} \mathrm{C}$ at a relative humidity of $85 \%$. The fruits were stored at desired temperature for at least 10 hours prior to test (Ahmadi et al., 2010). The maximum duration of test conducted on each fruit was 5 minutes, in order to reduce apple warming. A total number of 58 apples was tested. The curvature radius was measured by means of radius meter on the fruit parts, which were under the test (radius meter by LG with a resolution of $0.01 \mathrm{~mm}$, Fig. 1a). The fruit curvature radius measurement was carried out using Eq. 1 (Mohsenin, 1986; Fig. 1b):

$$
\text { Radius }=\frac{(A C)^{2}}{8(B D)}+\frac{(B D)}{2}
$$

where:

$A C$ - distance between $A$ and $C$ bars (mm); $B D$ - curvature between $A$ and $C$ bars ( $\mathrm{mm}$ )

Since apples cannot be considered completely spherical, the mean of harmonic curvature radius was calculated on the basis of the circumferential and the meridian radius at the impact area.

A pendulum was used to test the fruit; it was equipped with a $57.7 \mathrm{~cm}$ long wooden arm, an aluminium impactor, and a place to accommodate acceleration and force sensors. The accelerometer sensor (PCB 320c33, PCB Piezotronics, USA, sensitivity: $105.2 \mathrm{mV} \cdot \mathrm{g}^{-1}$ ) was placed on the rear sensor and then on the potentiometer sensor (PCB 208c02, PCB piezotronics, USA, sensitivity: $10.97 \mathrm{mV} \cdot \mathrm{N}^{-1}$ ), which was on the impactor head. An incremental optical encoder (Autonic E 5058, resolution: 0.018 , made in Korea) was also installed on the joint of pendulum bar (Fig. 2). The collision force was directly calculated by potentiometer, displacement rate by an accelerometer and displacement by an encoder, which basically measures the angular position of the impactor. These parameters were analysed by means of four-channel data processing system (ECON, AVANT Lite, model: MI-6004). The description of calculated parameters by the pendulum through the energy method has been described in detail by Abedi and Ahmadi (2013).
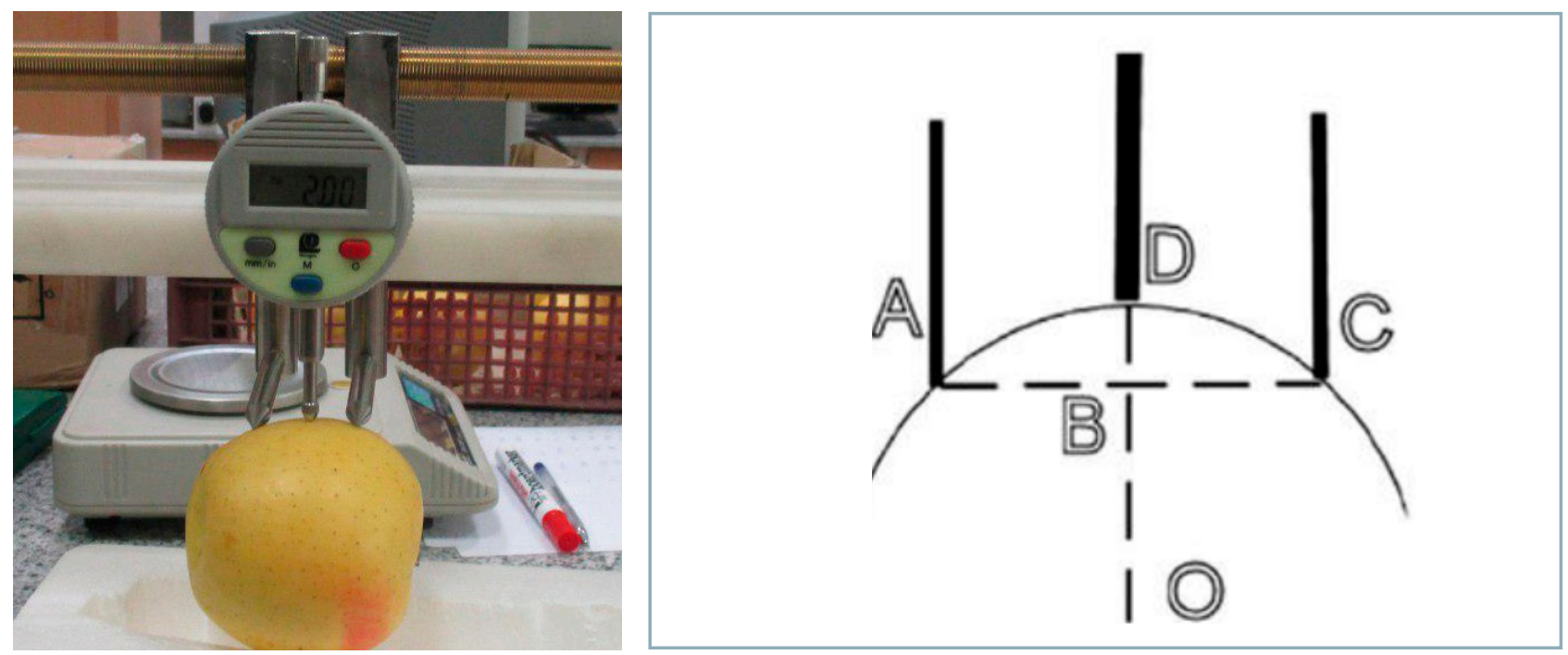

Fig. 1 Curvature radius meter (a); required dimensions to compute the curvature radius (b) 

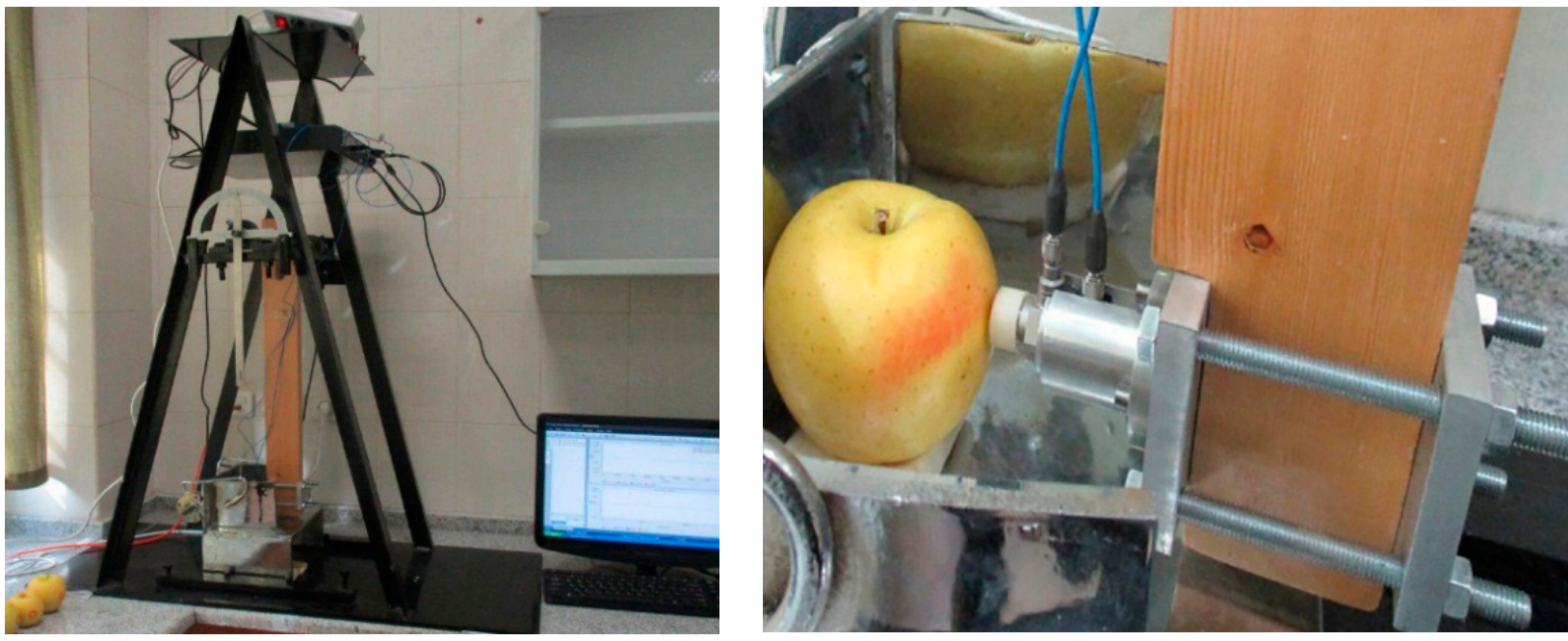

Fig. 2 Pendulum (a); impactor (b)

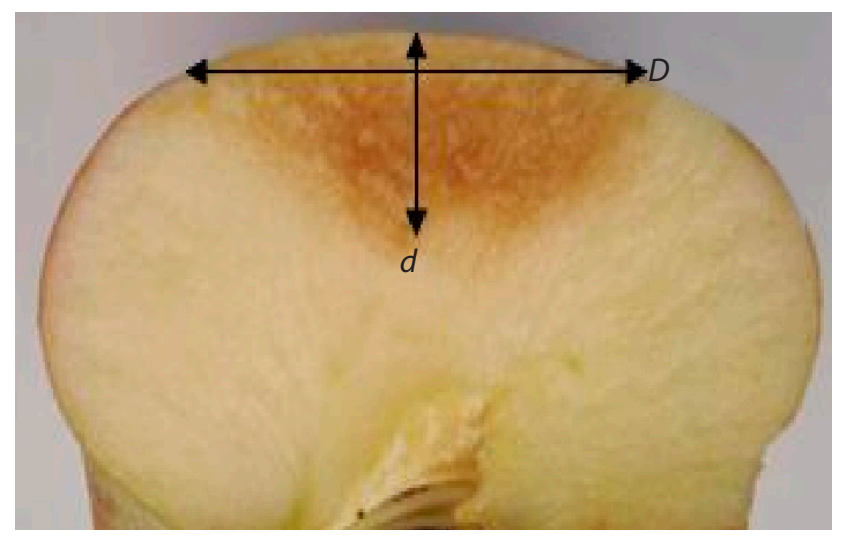

Fig. 3 Measurement of the diameter and depth of the bruise in apple cross section

The bruise volume was used as a dependent variable in bruise prediction models. The apple was observed after twenty-four hours post-impact; the diameter of the impacted bruise surface was measured, and subsequently, the thickness was measured by making a vertical shear perpendicular to the bruise surface (Fig. 3). Finally, the bruise volume was calculated according to the method used by Chen and San (1981):

$$
B V=\frac{\pi}{6} d D^{2}
$$

where:

$B V$ - bruise volume $\left(\mathrm{mm}^{3}\right) ; d$ - bruise depth $(\mathrm{mm}) ; D$ - bruise diameter ( $\mathrm{mm})$

Bruise prediction models include either impact energy, or maximum contact force at the moment of collision as major independent variables and other input factors are minor independent variables. Independent variables used in the regression and ANFIS models are: $\mathrm{E}$ - impact energy, J; $\mathrm{PF}$ - peak force, $\mathrm{N}$; two fruit temperatures (T) of 3 and $20^{\circ} \mathrm{C}$; $\mathrm{R}$ - curvature radius at the contact location, $\mathrm{mm}$; $\rho$ - apple density $\left(\mathrm{kg} \cdot \mathrm{m}^{-3}\right)$.
Multiple stepwise regression was used to form the bruising patterns. This method analyses were carried out in Minitab 18 software.

Adaptive neural network (ANFIS) as a basis for fuzzy inference systems

The principle of ANFIS is based on fuzzy inference system (FIS) input/output data. This system is based on the rules of combination of three components: membership functions of input/output variables (fuzzy), fuzzy rules (rule base), mechanism inference (combination of rules with fuzzy input), and output and system results characteristics (defuzzification) (Krueger et al., 2011). Frequently, ANFIS systems are using Takagi-Sugno-Kang (TSK) fuzzy system (TSK), which is a progressive network structure.

For simplicity, it was assumed that the fuzzy system has two inputs $-x$ and $y-$ and an output $-z$. The rules are as follows.

$$
\begin{aligned}
& \text { Rule 1: if } x \text { is } A_{1} \wedge y \text { is } B_{1} \text { then } f_{1}=P_{1} x+q_{1} y+r_{1} \\
& \text { Rule 2: if } x \text { is } A_{2} \wedge y \text { is } B_{2} \text { then } f_{2}=P_{2} x+q 2 y+r_{2}
\end{aligned}
$$

If the centre method is used for defuzzifying (converting the final system output to a classical number), the output will be as follows:

$$
f=\frac{w_{1}}{w_{1}+w_{2}} f_{1}+\frac{w_{2}}{w_{1}+w_{2}} f_{2}=\overline{w_{1}} f_{1}+\overline{w_{2}} f_{2}
$$

The ANFIS equivalent structure with five layers will be as follows (Fig. 4).

Layer 1 (input nodes): in this layer, the membership degree of input nodes to different fuzzy intervals is determined using the membership function:

$$
O_{i}^{1}=\mu_{A_{\mathrm{i}}}(x) \text { for } i=1,2 \wedge O_{i}^{1}=\mu_{B_{i}}(y) \text { for } i=1,2
$$

The Gaussian membership function $\mu_{A_{i}}(x)$ is expressed in terms of the parameter set $a_{i}, c_{i}$ (initial parameters) and the input $x$ of the $i^{\text {th }}$ node. 

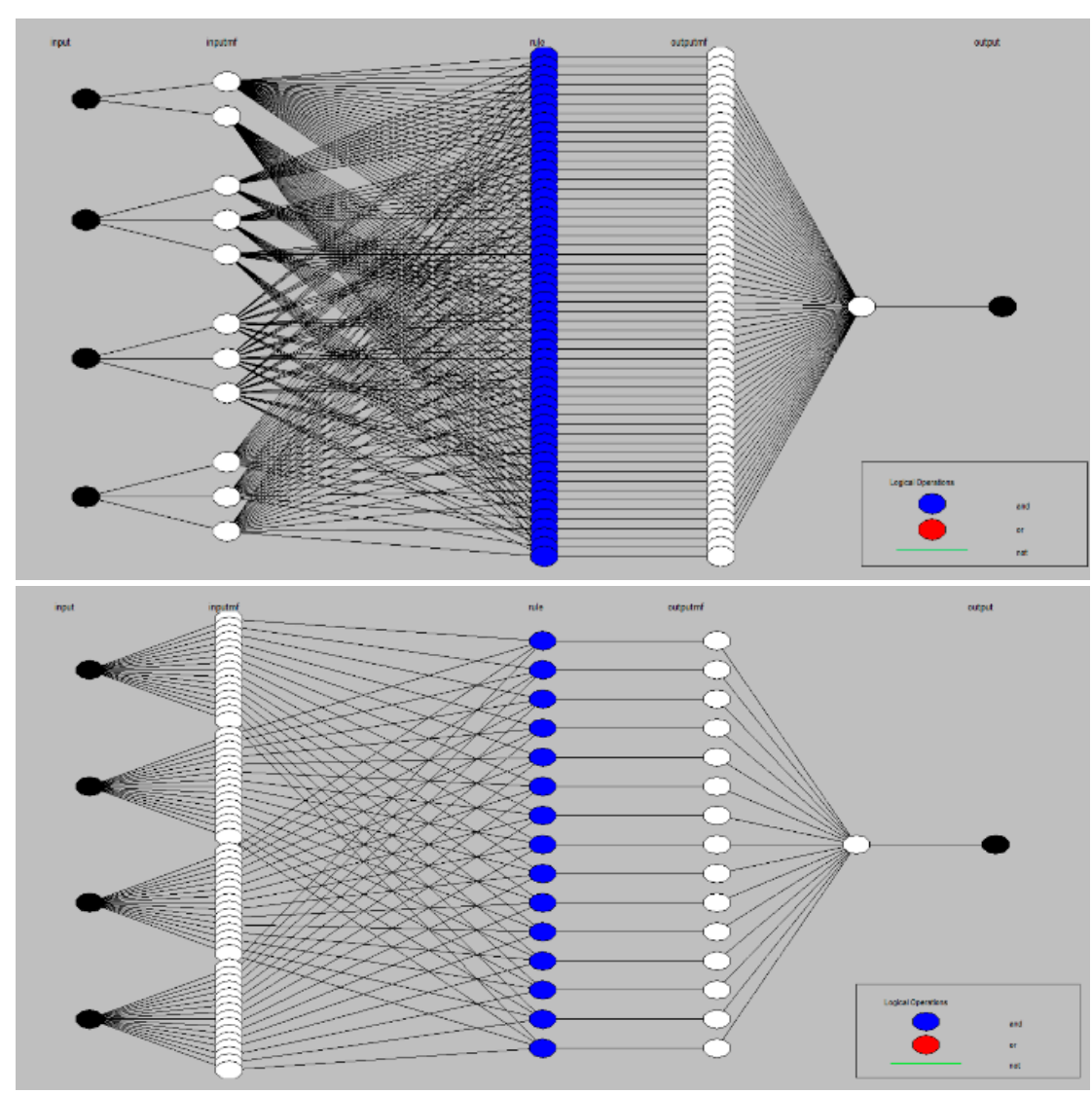

Fig. 4 The structure of the best ANFIS models for bruising prediction: Inference system using grid partitioning method (a); Inference system using subclustering method (b)

$$
\mu_{A_{i}}(x)=\exp \left[-\left(\frac{x-c_{i}}{a_{i}}\right)^{2}\right]
$$

Layer 2 (rule nodes): each node in this layer calculates the degree of a rule activity.

$$
O_{i}^{2}=w_{i}=\mu_{A i}(x) \times \mu_{B i}(\mathrm{y})
$$

$$
i=1,2
$$

Layer 3: the output of this layer is the normalized to the previous layer:

$$
O_{i}^{3}=\overline{w_{i}}=\frac{w_{i}}{w_{1}+w_{2}}
$$

$i=1,2$

Layer 4 (output nodes): in this output layer, each node is equal to:

$$
O_{i}^{4}=\bar{w}_{i} f_{i}=\overline{w_{i}}\left(P \mid i x+q_{i} y+r_{i}\right)
$$

Layer 5 (output nodes): in this layer, each node calculates the final output value as follows (the number of nodes is equal to the number of outputs):

Overall output $=O_{i}^{5}=\sum_{i} \bar{w}_{i} f_{i}=\frac{\sum_{i} w_{i} f_{i}}{\sum_{i} w_{i}}(11)$

The training of these systems means that educational data, the nonlinear parameters related to the fuzzy membership functions in the first layer and the linear parameters of the fourth layer are determined so that the desired output is obtained for the desired input. The hybrid training method is one of the most important methods for teaching the fuzzy inference systems based on the adaptive neural network. In this method, for the first layer, the method of post-propagation error is used, while in the fourth layer, the least squares estimation method is used (Jang and Sun, 1997). In this paper, several models were provided on the basis of preceding parameters in MATLAB software (Version7.12.0) and in Fuzzy Logic Toolbox.

\section{Results and discussion}

Several models were developed on the basis of the ANFIS techniques and stepwise regression to predict the bruise volume value. The first series of models used the maximum contact force as input parameter; the second series used the impact energy for this purpose. Among the developed models, models with a higher coefficient of determination $\left(R^{2}\right)$ were presented in Tables 1 and 2 in order to compare their performance. As shown in Tables 1 and 2, ANFIS models have the highest mean squared error (MSE) and determination coefficient $\left(R^{2}\right)$; the step-by-step regression models have the lowest determination coefficient $\left(R^{2}\right)$.

\section{Comparison of ANFIS models}

Among different ANFIS configurations, grid partitioning-based model had a higher $R^{2}$ than the sub-clustering model, but its execution time to get the fixed error took longer. This can be attributed to the number of rules created in each of these models. In a grid partitioning-based model, the space of each input is divided into equal intervals, and a rule is set in each of the multidimensional spaces derived from all different input combinations. As a result, the number of rules increases with increasing inputs. In a sub-clustering model, data mining is first performed on a data set; the spaces, in which there is a higher number of data, are identified for each input, and instead of dividing inputs into equal intervals in areas, in which the number of data is greater, membership functions are created with smaller intervals. Therefore, rules are created only in certain domains and the number of rules decreases. Fig. 4 shows the general structure of the two network separation methods. It also demonstrates different clustering, in which the grid partitioning has 54 rules and the sub-clustering model has 15 rules. The higher the number of rules, the more precise and slower the network execution. Such behaviour has also been reported by Ay and Kisi (2014). 
Table 1 Results of adaptive neuro-fuzzy inference system and stepwise regression for the bruise volume prediction on the basis of maximum contact force $(F)$, curvature radius $(R)$, temperature $(T)$ and mass $(M)$

\begin{tabular}{|c|c|c|c|c|c|c|c|}
\hline \multirow[t]{2}{*}{ Model } & \multicolumn{2}{|c|}{ Type of MF } & \multicolumn{2}{|c|}{ Number of MF } & \multirow[t]{2}{*}{ Optimization method } & \multirow[t]{2}{*}{ RMSE } & \multirow[t]{2}{*}{$R^{2}$} \\
\hline & input & output & input & epoch & & & \\
\hline Grid partitioning & trimf & linear & 2333 & 20 & hybrid & 0.00017625 & 1 \\
\hline Grid partitioning & gaussmf & linear & 2333 & 20 & hybrid & 0.00059748 & 1 \\
\hline Grid partitioning & tramf & linear & 2333 & 20 & hybrid & 0.00017041 & 1 \\
\hline \multirow{2}{*}{ Grid partitioning } & gbellmf & linear & 2333 & 20 & hybrid & 0.0011199 & 1 \\
\hline & reject ratio & accept ratio & \multicolumn{2}{|c|}{ squash factor } & range of influence & \multicolumn{2}{|c|}{-} \\
\hline Sub-clustering & 0.15 & 0.5 & 1.25 & & 0.5 & 0.0020133 & 1 \\
\hline Regression & \multicolumn{5}{|c|}{$B V=103.821+T-2.595 R+4.037 F-0.334 \mathrm{M}$} & - & 0.6842 \\
\hline
\end{tabular}

Table 2 Comparative neural fuzzy inference system and stepwise regression for the bruise volume prediction on the basis of impact energy $(E)$, curvature radius $(R)$, temperature $(T)$, mass $(M)$

\begin{tabular}{|c|c|c|c|c|c|c|c|}
\hline \multirow[t]{2}{*}{ Model } & \multicolumn{2}{|c|}{ Type of MF } & \multicolumn{2}{|c|}{ Number of MF } & \multirow[t]{2}{*}{ Optimization method } & \multirow[t]{2}{*}{ RMSE } & \multirow[t]{2}{*}{$\mathbf{R}^{2}$} \\
\hline & input & output & input & epoch & & & \\
\hline Grid partitioning & trimf & linear & 2333 & 20 & hybrid & 0.00016625 & 1 \\
\hline Grid partitioning & gaussmf & linear & 2333 & 20 & hybrid & 0.00023578 & 1 \\
\hline Grid partitioning & tramf & linear & 2333 & 20 & hybrid & 0.00015941 & 1 \\
\hline \multirow{2}{*}{ Grid partitioning } & gbellmf & linear & 2333 & 20 & hybrid & 0.0011012 & 1 \\
\hline & reject ratio & accept ratio & \multicolumn{2}{|c|}{ squash factor } & range of influence & \multicolumn{2}{|c|}{-} \\
\hline Sub-clustering & 0.15 & 0.5 & \multicolumn{2}{|c|}{1.25} & 0.5 & 0.0033166 & 1 \\
\hline Regression & \multicolumn{5}{|c|}{$B V=128.143+0.854 T-1.459 R+2,559.185 E-0.318 \mathrm{M}$} & - & 0.6954 \\
\hline
\end{tabular}

\section{Membership functions comparison}

Four types of the most common fuzzy membership functions were used in this study. These functions include Gaussian, triangular, trapezoidal, and generalized bell functions (Fig. 5). For both models, the trapezoidal membership function showed the maximum contact force, as well as impact energy, having the best performance and

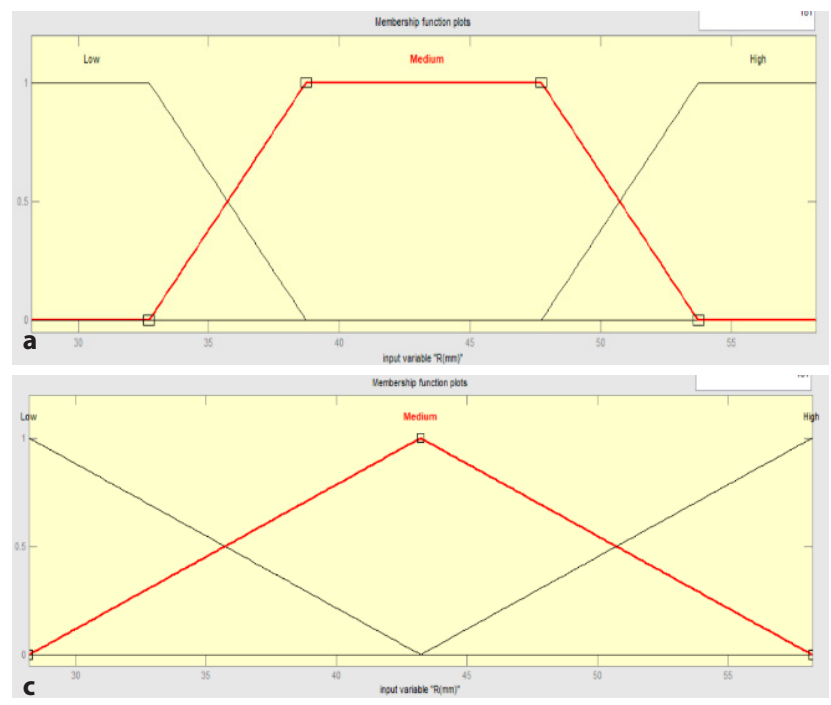

the lowest mean squared error (MSE). The triangular and Gaussian membership functions are ranked the second in terms of performance, respectively. Such functions are also derived from the membership functions in other researches (Taghavifar and Mardani, 2014).
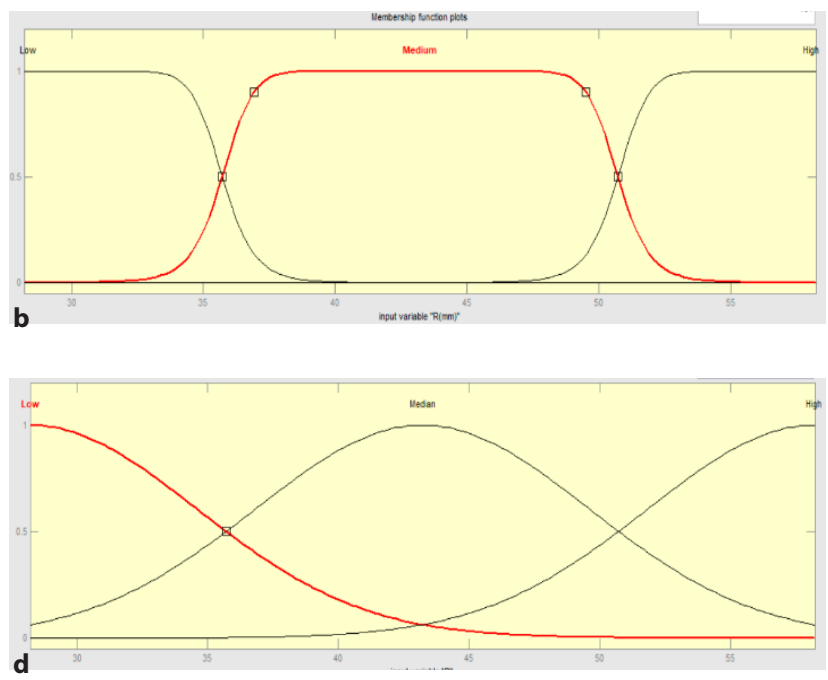

Fig. 5 Membership functions

a - trapezoidal; b - generalized bell; c - triangular; $d$ - Gaussian 
Table 3 Statistical characteristics of stepwise regression model for the bruise volume prediction (BV) on the basis of maximum force $(F)$; curvature radius $(R)$; temperature $(T)$; mass $(M)$

\begin{tabular}{|c|c|c|c|c|c|c|}
\hline \multirow[t]{2}{*}{ Model } & \multirow{2}{*}{$\begin{array}{c}\text { Equation } \\
\text { parameters }\end{array}$} & \multicolumn{2}{|c|}{ Unstandardized coefficients } & \multicolumn{3}{|c|}{ Standardized coefficients } \\
\hline & & B & Std. error & Beta & $t$ & sig \\
\hline \multirow{5}{*}{$\begin{array}{l}B V=103.821 \\
+T-2.595 R+ \\
4.037 F-0.334 M\end{array}$} & constant & 103.821 & 75.113 & & 1.382 & 0.179 \\
\hline & $\mathrm{T}$ & 1.000 & 1.273 & 0.082 & 0.786 & 0.439 \\
\hline & $\mathrm{R}$ & -2.595 & 2.118 & -0.168 & -1.225 & 0.232 \\
\hline & $\mathrm{F}$ & 4.037 & 0.524 & 0.801 & 7.708 & 0.000 \\
\hline & $M$ & -0.334 & 0.381 & -0.110 & -0.875 & 0.390 \\
\hline
\end{tabular}

Table 4 Statistical characteristics of stepwise regression model for the bruise volume prediction (BV) on the basis of impact energy $(E)$; curvature radius $(R)$; temperature $(T)$; mass $(M)$

\begin{tabular}{|c|c|c|c|c|c|c|}
\hline \multirow[t]{2}{*}{ Model } & \multirow{2}{*}{$\begin{array}{c}\text { Equation } \\
\text { parameters }\end{array}$} & \multicolumn{2}{|c|}{ Unstandardized coefficients } & \multicolumn{3}{|c|}{ Standardized coefficients } \\
\hline & & B & Std. error & Beta & $t$ & sig \\
\hline \multirow{5}{*}{$\begin{array}{l}B V=128.143+ \\
0.854 T-1.459 R \\
+2,559.185 E \\
-0.318 M\end{array}$} & constant & 128.143 & 74.459 & & 1.721 & 0.098 \\
\hline & $\mathrm{T}$ & 0.854 & 1.293 & 0.070 & 0.666 & 0.515 \\
\hline & $\mathrm{R}$ & -1.459 & 2.210 & -0.094 & -0.660 & 0.515 \\
\hline & $E$ & 2559.185 & 339.202 & 0.819 & 7.545 & 0.000 \\
\hline & $M$ & -0.318 & 0.387 & -0.105 & -0.823 & 0.418 \\
\hline
\end{tabular}

\section{Comparison of regression models}

Two different models were developed to predict the bruise volume. The first model used the maximum contact force as an independent variable and the second model used the impact energy as an independent variable. Both models provided relatively low performance in terms of prediction. Both models showed determination coefficient $R^{2}$ of 0.758 and 0.776 for the maximum contact force and impact energy models, respectively. The statistical analysis of data of these models are shown in Tables 3 and 4, respectively. These results can be attributed to the nonlinear behaviour of biological materials under the effect of mechanical changes, which makes it difficult to model such phenomena using regression models. Impact energy-based models, as they have been mentioned by multiple researchers (Ahmadi et al., 2010; Abedi and Ahmadi 2013), are more capable of the bruise volume prediction. The reason is that the maximum contact force depends on its sub-variables: temperature, stiffness, bending radius, etc.

\section{Observation of the surface curves}

The output results of the ANFIS models are threedimensional diagrams, which indicate the effect of changes in input parameters on the output $(T, R, F, M$ are input variables and $B V$ is the model output, Fig. $6 A, B$ ). As shown in Fig. $6 \mathrm{~A}, \mathrm{~B}$ a, b, $\mathrm{d}$, with an increase in the maximum contact force, the bruise volume also greatly increased, which has been reported in numerous studies (Ahmadi et al. 2010; Van Linden et al., 2006). The fruit bruise from the impact varies on the basis of fruit tissue and environment temperature. At lower temperatures, the force effect on the bruise is considered much more severe. According to Fig. 6A, B a, d, e, it is evident that, in fruits with a smaller curvature radius, more damage occurred due to the impact. The fact is that, at
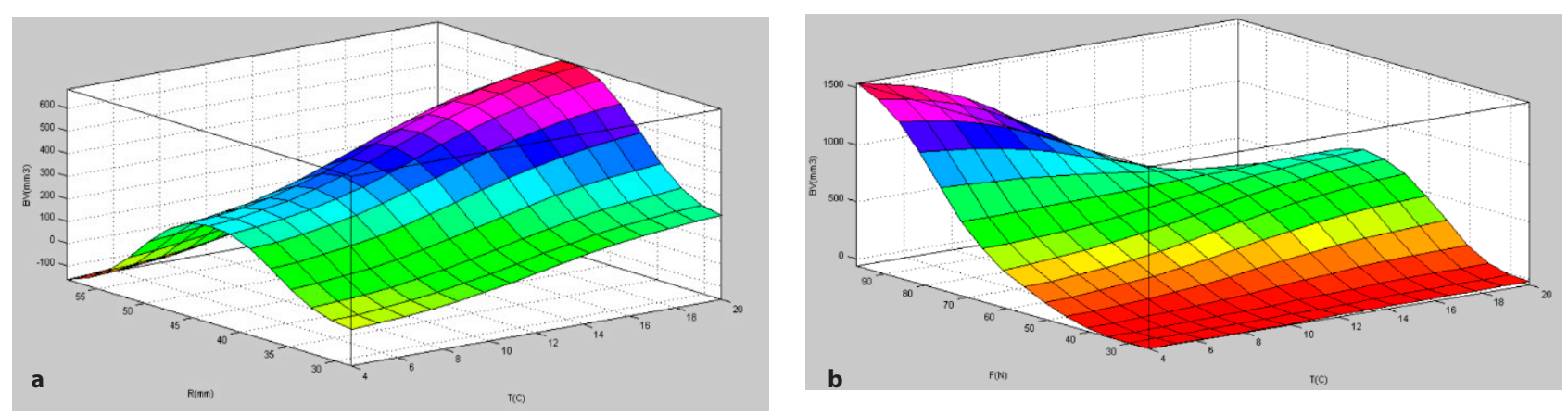

Fig. 6A 3D Curves of the bruise volume versus effects of input factors $a$ - temperature - curvature radius; $b$ - temperature - maximum force 

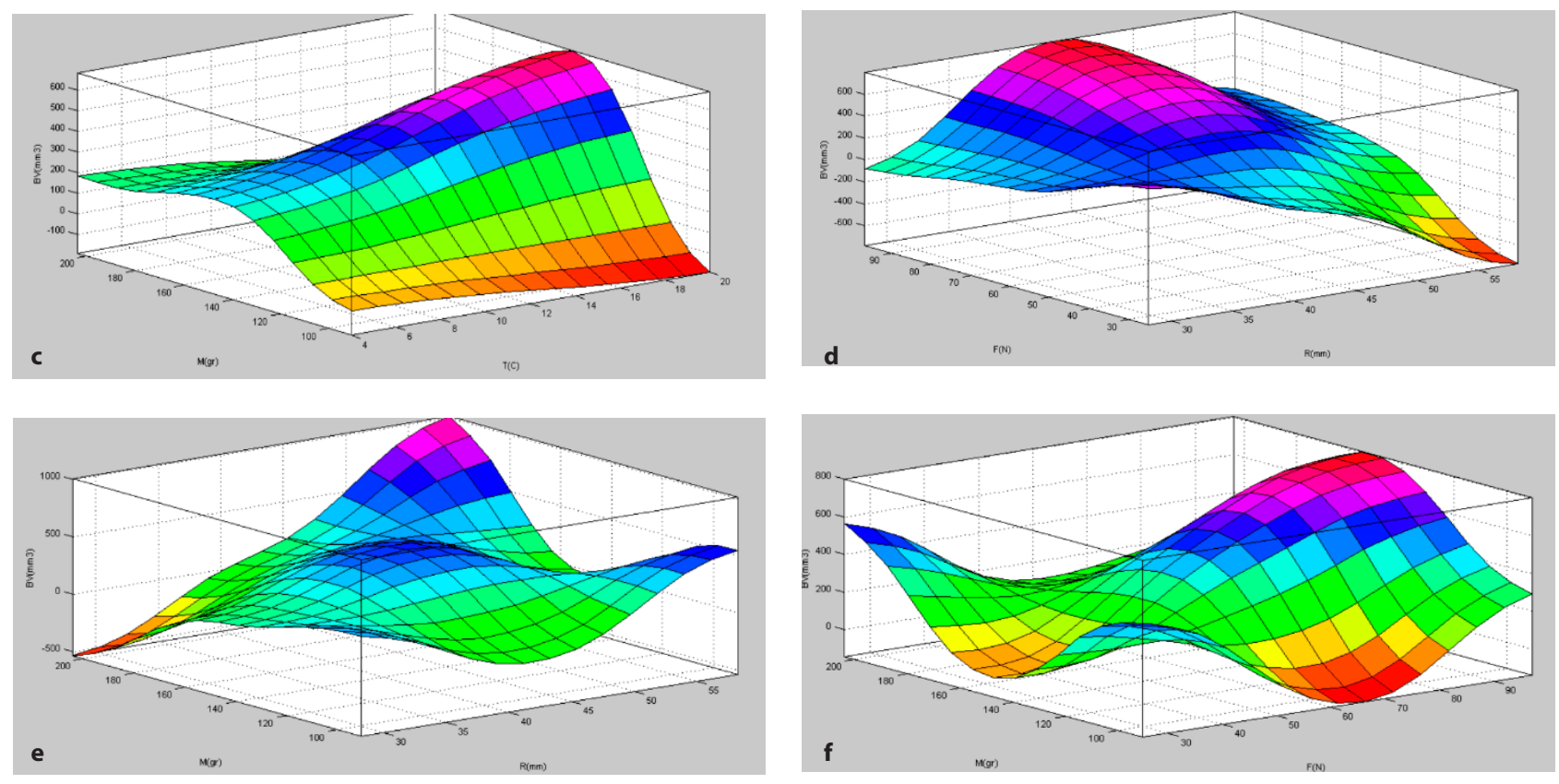

Fig. 6B 3D Curves of the bruise volume versus effects of input factors

$c$ - temperature - mass; $d$ - curvature radius - maximum force; $\mathrm{e}$ - curvature radius - mass; $f$ - maximum force - mass

the point in which the impact occurs, if the curvature radius and area under tension are small, the tension will be greater at this point (Ahmadi et al., 2010). Given the existing forms, it is not possible to give a definitive account of the temperature effect on the bruise volume. In Fig. $6 \mathrm{~A} \mathrm{~b}, \mathrm{c}$, the bruise volume decreases with increasing temperature; however, in Fig. $6 \mathrm{~A}$ $a$, there is almost a different trend in the temperature effect on the fruit bruise volume. This can be due to other factors involved in this phenomenon, the effect of which cannot be ignored. Therefore, careful examination of the temperature effect on the bruise volume by conduction of special tests and analyses is recommended.

\section{Conclusion}

1. ANFIS models presented a much better performance than regression models in terms of the bruise volume prediction. All ANFIS models showed a coefficient of determination value exceeding 0.95 , while regression models reached a coefficient of determination of less than 0.7 .

2. Among the ANFIS models, the created models based on the grid partitioning method were more accurate; however, the models based on the sub-clustering mode had faster runtime.

3. Models using impact energy as an independent variable under all ANFIS conditions, as well as regression models, showed better accuracy than the models using maximum contact force models as an independent variable.

\section{References}

ABEDI, G. - AHMADI E. 2013. Design and evaluation a pendulum device to study postharvest mechanical damage in fruits: Bruise modeling of red delicious apple. In Australian Jourdan of Crop Science, vol. 7, no. 7, pp. 962-968.
AHMADI, E. - BARIKLOO, H. - KASHFI, M. 2016. Viscoelastic finite element analysis of the dynamic behavior of apple under impact loading with regard to its different layers. In Computers and Electronics in Agriculture, vol. 121, pp. 1-11.

AHMADI, E. - GHASSEMZADEH, H. R. - SADEGHI, M. - MOGHADDAM, M. - ZARIFNESHAT, S. 2010. The effect of impact and fruit properties on the bruising of peach. In Journal of Food Engineering, vol. 97, pp. 110-117.

AMIRYOUSEFI, M. R. - MOHEBBI, M. - KHODAIYAN, F. - ASADI, S. 2011. An empowered adaptive neuro-fuzzy inference system using self-organizing map clustering to predict mass transfer kinetics in deep-fat frying of ostrich meat plates. In Computers and Electronics in Agriculture, vol. 76, pp. 89-95.

AY, M. - KISI, O. 2014. Modelling of chemical oxygen demand by using ANNs, ANFIS and k-means clustering techniques. In Journal of Hydrology, vol. 511, pp. 279-289.

ALTUG, S. - CHOW, M. Y. - TRUSSELL, H. J. 1999. Fuzzy inference systems implemented on neural architectures for motor fault detection and diagnosis. In IEEE Transactions on Industrial Electronics, vol. 46, no. 6, pp. 1069-1079.

BARREIRO, P. - STEINMETZ, V. - RUIZ-ALTISENT, M. 1997. Neural bruise prediction models for fruit handling and machinery evaluation. In Computers and Electronics in Agriculture, vol. 8, pp. 91-103.

CHEN, P. - SUN, Z. 1981. Impact parameters related to postharvest bruising of apples. ASAE Paper No. 81, pp. 3041, St. Joseph, Michigan.

DIEZMA, B. - VALERO, C. - GARCIA-RAMOS, F. J. - RUIZ-ALTISENT, M. 2006. Monitoring of firmness evolution of peaches during storage by combining acoustic and impact methods. In Journal of Food Engineering, vol. 77, pp. 926-935.

DU, C. J. - SUN, D. W. 2006. Learning techniques used in computer vision for food quality evaluation: a review. In Journal of Food Engineering, vol. 72, no. 1, pp. 39-55.

EFFENDI, Z. - RAMLI, R. - GHANI, J. A. 2010. A back propagation neural networks for grading Jatropha curcas fruits maturity. In American Journal of Applied Sciences, vol. 7, no. 3, pp. 390-394. 
JANG, J. S. R. - SUN, C. T. 1997. Neuro-fuzzy modeling and control. In Proceedings of IEEE, vol. 83, no. 3, pp. 378-405.

JHIN, C. - HWANG, K. T. 2014. Prediction of radical scavenging activities of anthocyanins applying adaptive neuro-fuzzy inference system (ANFIS) with quantum chemical descriptors. In International Journal of Molecular Sciences, vol. 15, pp. 14715-14727.

KARAMAN, S. - KAYACIER, A. 2011. Effect of temperature on rheological characteristics of molasses: Modeling of apparent viscosity using Adaptive Neuro-Fuzzy Inference System (ANFIS) In LWT-Food Sciences, vol. 44, pp. 1717-1725.

KHOSHHAL, A. - ALIZADEH, A. - ETEMADI, A. - ZERESHKI, S 2010. Artificial neural network modeling of apple drying process. In Journal of Food Process Engineering, vol. 33, pp. 298-313.

KHOSHNEVISAN, B. - RAFIEE, S. - OMID, M. - MOUSAZADEH, H. 2014. Prediction of potato yield based on energy inputs using multilayer adaptive neuro-fuzzy inference system. In Measurement, vol. 47, pp. 521-530.

KRUEGER, E. - PRIOR, S. A. - KURTENER, D. - ROGERS, H. H. - RUNION G. B. 2011. Characterizing root distribution with adaptive neurofuzzy analysis. In International Agrophysics, vol. 25, pp. 93-96.

LEWIS, R. - YOXALL, A. - MARSHALL, M. B. - CANTY, L. A. 2008. Characterising pressure and bruising in apple fruit. In Wear, vol. 264, pp. 37-46.

MENESATTI, P. - PAGLIA, G. 2001. Development of a drop damage index of fruit resistance to damage. In Journal of Agricultural Engineering Research, vol. 80, pp. 53-64.
MOHSENIN, N. N. 1986. Physical Properties of Plant and Animal Materials. Gordon and Breach Science Publishers, New York.

MOINFAR, A. - SHAHGHOLI, G. 2019. The effect of tractor driving system type on its slip and rolling resistance and its modelling using ANFIS. In Acta Technologica Agriculturae, vol. 4, pp. 116-122. ROTH, E. - KOVACS, E. - HERTOG, M. - VANSTREELS, E. - NICOLAI, B. 2005. Relationship between physical and biochemical parameters in apple softening. In Proceedings of the $5^{\text {th }}$ International Postharvest Symposium (PS'05), ISHS, pp. 573-578.

TAGHAVIFAR, H. - MARDANI, A. 2014. On the modeling of energy efficiency indices of agricultural tractor driving wheels applying adaptive neuro-fuzzy inference system. In Journal of Terramechanics, vol. 56, no.1, pp. 37-47.

VAN LINDEN, V. - SCHEERLINCK, N. - DESMET, M. - DE BAERDEMAEKER, J. 2006. Factors that affect tomato bruise development as a result of mechanical impact. In Postharvest Biology and Technology, vol. 42, pp. 260-270.

VAN ZEEBROECK, M. - VAN LINDEN, V. - DARIUS, P. - DE KETELAERE, B. - RAMON, H. - TIJSKENS, E. 2007. The effect of fruit factors on the bruise susceptibility of apples. In Postharvest Biology and Technology, vol. 46, pp.10-19.

ZHENG, H. - FANG, S. S. - LOU, H. Q. - CHEN, Y. - JIANG, L. L. - LU, H. F. 2011. Neural network prediction of ascorbic acid degradation in green asparagus during thermal treatments. In Expert Systems with Applications, vol. 38, pp. 5591-5602. 